\title{
As vulnerabilidades dos documentos digitais: Obsolescência tecnológica e ausência de políticas e práticas de preservação digital
}

\author{
Henrique Machado dos Santos \\ Daniel Flores \\ Universidade Federal de Santa Maria - UFSM, Brasil
}

REVIEW

\begin{abstract}
Resumo
Objetivo. Este trabalho procura debater os pontos teóricos referentes à obsolescência tecnológica, implementação de políticas organizacionais, estratégias de preservação e sistemas informatizados.

Método. Desenvolve-se o levantamento bibliográfico de materiais previamente publicados, como livros, teses, sítios da Internet e artigos de periódicos científicos indexados no Google Scholar e Portal de periódicos da CAPES. A coleta de dados tem como base a análise qualitativa, e realiza uma revisão de literatura capaz de apresentar o estado da arte sobre a preservação e a fragilidade dos documentos digitais.

Resultados. Entre os resultados pode-se considerar a obsolescência tecnológica uma consequencia da própria tecnologia motivada por uma evolução desenfreada. Desta forma, vem atingindo softwares, formatos de arquivo, sistemas operacionais e profissionais responsáveis pela preservação, e assim coloca um parte significativa da memória das sociedades contemporâneas em risco.

Conclusões. Destaca-se a importância da políticas institucionais, das estratégias de preservação digital e dos sistemas informatizados. Através destes será possível planejar, monitorar e tratar os documentos digitais, minimizando os efeitos da obsolescência tecnológica com a finalidade de preservar seu conteúdo e sua fidedignidade.
\end{abstract}

Palavras-chave

Documento digital ; Documento eletrônico ; Obsolescência tecnológica ; Preservação digital ; Tecnologia da informação

The vulnerabilities of digital documents: Technological obsolescence and lack of policies and practices of digital preservation

\begin{abstract}
Objective. This paper attempts to discuss the theoretical issues related to the technological obsolescence, implementation of organizational policies, preservation strategies and computerized systems.

Method. It develops the literature previously published materials such as books, theses, websites and articles in scientific journals indexed in Google Scholar and CAPES Journal Portal. Data collection is based on qualitative analysis, and performs a literature review can provide state of the art on preserving and fragility of digital documents.

Results. Among the results can be considered the technological obsolescence as consequence of the technology itself motivated by unbridled development. In this way, it has been reaching software, file formats, operating systems and professionals responsible for preservation, and thus a significant part of the memory of contemporary societies is at risk. Conclusions. It highlights the importance of institutional policies, digital preservation strategies and computerized systems. Through these is can plan, monitor and treat digital documents, minimizing the effects of technological obsolescence in order to preserve its content and its reliability.
\end{abstract}

Keywords

Digital document ; E-document ; Technological obsolescence ; Digital preservation ; Information technology 


\section{Introdução}

A sociedade contemporânea vive uma nova era onde a presença da informação registrada em bytes tem um significado muito maior do que se pode imaginar (LOPES, L., 1997). A demanda por tecnologias da informação atingiu diversos setores da sociedade, desta forma, um grande fluxo de dados está circulando por meio de computadores.

Há de se destacar que as organizações públicas e privadas, assim como os cidadãos, estão produzindo cada vez mais documentos em formato digital com certa diversidade (CONARQ, 2004). Neste sentido, o funcionamento das organizações depende cada vez mais de informações, em maior número, diversidade e complexidade se comparadas ao passado (LOPES, L., 1996). As ferramentas de tecnologias da informação ocupam um lugar de destaque na sociedade, e já são indispensáveis ao progresso científico, tecnológico e econômico.

Muitas coleções digitais importantes estão sendo construídas fora das bibliotecas e dos arquivos por diferentes organizações, ou sendo publicadas diretamente na Internet. Com o aumento da produção de informação em formato digital, tem sido questionada cada vez mais a importância de garantir a sua disponibilização e preservação por grandes períodos de tempo (MÁRDERO ARELLANO, 2008, p. 43).

As organizações de modo geral não estão habituadas a preservar materiais, sejam eles digitais ou analógicos. Salvo a exceção de bibliotecas, arquivos e centros de documentação e informação, é difícil imaginar quem está preparado para preservar documentos digitais em longo prazo. Não é exagero afirmar que os próprios responsáveis pela preservação, como bibliotecas e arquivos, estão com dificuldades para se adaptar a esta nova realidade. Conceitos necessitam ser reformulados e novas teorias precisam ser criadas para contemplar o lado digital da documentação.

No contexto atual, há conteúdos de valor relevante que estão sendo produzidos fora das instituições de memória, e que de alguma forma precisam ser preservados para atender aos respectivos fins que motivaram a sua criação. Entretanto ainda não há uma grande preocupação das organizações de modo geral para a questão da preservação digital.

O presente estudo realiza um levantamento bibliográfico de materiais previamente publicados, como livros, teses, sítios da Internet e artigos de periódicos científicos indexadas no Google Scholar e no Portal de periódicos da CAPES ${ }^{1}$. Os dados coletados são analisados de forma qualitativa e estruturados em seções temáticas. Desta forma, o artigo tem por objetivo realizar uma revisão de literatura que determine o estado da arte sobre a preservação e a fragilidade dos documentos digitais, apontando os principais entraves teóricos (GIL, 1991; LUNA, 1997; SILVA; MENEZES, 2005).

\section{Do avanço a dependência}

As tecnologias da informação evoluíram em um ritmo muito acelerado, e nesta corrida por mais competitividade e por mais eficiência, surgiram diversas ferramentas que rapidamente se fixaram nas práticas comuns a organizações e pessoas. Há notáveis mudanças quanto a comunicação, em virtude do advento dos computadores e da Internet que desencadeou transformações profundas no mundo moderno. O velho fluxo por onde circulava o dado, a informação, o documento e o conhecimento, de modo geral, teve de ser reformulado, isto porque o fascínio proporcionado pelas novas tecnologias extrapolou as perspectivas dos indivíduos, levando a uma forte demanda tecnológica.

A introdução e a respectiva aceitação do documento digital na sociedade contemporânea podem ser justificadas pela sua facilidade de criar, editar, excluir e disseminar o conteúdo. Entretanto, as suas complexidades e especificidades aumentam na mesma medida que suas funcionalidades.

Um documento digital pode estar representado em um ou vários objetos digitais, em diversos formatos lógicos, e pode ser suportado por grande variedade de representações físicas. A sua dependência de software tem origem em sua natureza binária, armazenada em forma codificada, apenas legível por programas. Sem esses programas, os objetos digitais não podem ser acessados, lidos ou impressos (MÁRDERO ARELLANO, 2008, p. 47).

Os documentos digitais podem representar diversos conteúdos, além disso, a leitura destes é realizada através de um conjunto de tecnologias que estão em constante mudança. Muito diferente da leitura de forma direta que acontece com os documentos em papel. Desta forma, os primeiros sinais de dependência tecnológica surgiram 
a partir do momento em que parte da informação produzida começou a ser registrada em suportes eletrônicos, os quais são acessíveis somente por meio de equipamentos eletrônicos. Assim, computador passou a registrar informações que não estão disponíveis em outros meios, senão o digital.

Uma parte significativa da informação produzida no mundo tem origem no meio digital, havendo ainda uma grande diversidade quanto à forma e aos formatos de arquivo. Em contrapartida, hardware, software, e suportes estão em constantemente evolução, ocasionando mudanças para as gerações mais novas, o que por vezes gera a incompatibilidade com as tecnologias anteriores (THOMAZ, 2006). Esta constante mudança das tecnologias é uma das grandes indagações da preservação digital, pois há de se preservar documentos produzidos no passado, no presente, e ainda, aqueles que serão produzidos no futuro, provavelmente mais complexos.

Após a adesão das ferramentas de tecnologia da informação e do próprio documento digital pela sociedade, não se questionou a sua permanência neste cenário. Isto fez com que todas as inovações posteriores fossem aceitas a priori sem qualquer análise, isto porque não se pensou em diferenciar as tecnologias mais "simples" das mais "complexas". Tal fato torna a preservação digital um grande dilema, pois não se tem controle dos avanços da tecnologia, e mesmo assim, documentos digitais continuam sendo produzidos.

As atividades de preservação digital se tornam mais complexas quando os documentos possuem recursos de interatividade caracterizados como elementos indispensáveis para a sua correta representação (SANTOS, H.; FLORES, 2014). Estes elementos de interatividade são uma peculiaridade dos formatos digitais e exigem um tratamento diferenciado em virtude de suas funcionalidades.

Não há como negar a forte influência que as tecnologias da informação estão exercendo sobre a sociedade como um todo. Como resultado de parte dessa evolução, o documento digital, está sendo disseminado nos mais diversos segmentos, fato que é facilmente justificado pela sua praticidade. Nesse sentido há um grande volume de dados e informações registrados em documentos digitais, os quais dependem de um conjunto de equipamentos computacionais para a sua correta interpretação. O conhecimento de modo geral, esta dependendo fortemente destes registros contemporâneos.

O fato determinante é que as atividades pesquisa [...] estão crescentemente dependentes de materiais digitais. Para que haja avanço do conhecimento científico com um nível mais aceitável de duplicação de esforços, é necessário o estabelecimento de metodologias e compromissos de longo prazo que garantam a capacidade dos dados em formatos digitais, que estão sendo gerados agora, de serem acessados, interpretados e reutilizados com a tecnologia corrente à época do acesso. Portanto, o arquivamento persistente, a preservação digital e o estabelecimento de modelos de informação para a preservação de registros científicos estão se tornando questões chave para as áreas de pesquisa (SAYÃO; SALES, 2012, p. 180).

Os registros digitais tem um significado histórico de valor único, embora os documentos digitais sejam muito vulneráveis em comparação com outros métodos de registro como em papel. Sendo assim, a memória da história contemporânea corre sérios riscos (ROTHENBERG, 1999). Para evitar tamanha catástrofe, é preciso conhecer as vulnerabilidades das tecnologias a fim de minimizar os riscos de perda.

\section{A fragilidade da inovação}

A era da sociedade da informação proporcionou facilidades para criar documentos, dados e informações. Entretanto estes registros podem ser facilmente perdidos, pois "a humanidade ainda não tem prática e nem experiência para a memória digital" (INNARELLI, 2007, p. 28). Ou seja, ainda não há um corpo de conhecimentos que seja capaz de garantir a preservação dos documentos digitais em longo prazo.

Para muitos documentos analógicos, a preservação do suporte e sua forma física garantem a conservação de seu conteúdo. Uma fotografia ou uma carta que fique guardada em condições ambientais adversas (calor e/ou umidade, por exemplo), ainda que apresente traços de deterioração, pode ser contemplada, e seu conteúdo é legível. Exemplos famosos são os inúmeros pergaminhos, tabuletas de argila, a pedra de Roseta, cópias produzidas em mosteiros medievais, entre outros registros culturais e artísticos das mais antigas civilizações e de períodos relativamente recentes da nossa história, que sobreviveram ao tempo mesmo sem cuidados especiais (CORRÊA, 2010, p. 24). 
Os documentos em suportes tradicionais possuem muito mais resistência se comparados aos documentos digitais. O ponto a ser destacado é que os documentos tradicionais podem resistir ao tempo sem nenhum tratamento e mesmo assim será possível realizar a leitura direta.

Os documentos digitais são frágeis e os sistemas de gestão não garantem segurança e nem a preservação digital em longo prazo. A fragilidade pode estar relacionada com fatores como a sua rápida degradação física, obsolescência tecnológica, complexidade e nos custos relacionados com a preservação. Além disso, é preciso profissionais especializados para todas as áreas envolvidas no processo de preservação (MÁRDERO ARELLANO, 2008).

A qualificação se tornou fundamental para a preservação de documentos digitais, pois é preciso considerar a necessidade de desenvolver um corpo de conhecimentos sobre a preservação destes registros. Desta forma, as questões centrais devem ser definidas nas políticas de preservação digital e executadas por profissionais capacitados.

\section{Obsolescência tecnológica}

A história da humanidade é marcada por transformações, dentre elas, os avanços tecnológicos ocorridos durante o século $X X$ e início do século $X X I$, especialmente no âmbito das tecnologias da informação e comunicação. Como consequência destes avanços qualquer documento produzido em suporte tradicional pode ser produzido ou representado em meio digital. Desta forma, as atividades de pesquisa em preservação digital se tornaram questões fundamentais (BODÊ, 2007; INNARELLI, 2007; SANTOS, V., 2005).

A especificidade dos documentos digitais em seus contextos tecnológicos afeta diretamente o acesso e o uso de seus conteúdos, aumentando a complexidade da gestão de acervos digitais. Deste modo, a fragilidade do documento digital é um dos grandes desafios contemporâneos para a comunidade de profissionais e pesquisadores (SAYÃO, 2010). Diante desta situação, a cooperação entre arquivos, bibliotecas, museus, editores e desenvolvedores, torna-se fundamental para salvaguardar a memória coletiva (SARAMAGO, 2004). Ressalta-se ainda que arquivos, bibliotecas, centros de documentação e museus têm o papel de mediar à recuperação da informação, atendendo aos diversos interesses do público geral (BELLOTTO, 2006). Os documentos em meio digital nunca sobreviverão de maneira inerte da mesma forma que os seus equivalentes em suporte tradicional (SAYÃO; SALES, 2012), pois eles correm um risco contínuo durante sua existência (SANTOS, H.; FLORES, 2014b), e dependem das tecnologias para serem preservados e acessados.

Desta forma, a obsolescência tecnológica é a principal dificuldade para a preservação digital em longo prazo (HEDSTROM, 2001; SANTOS, V., 2005), e pode se manifestar em nível de hardware, software e suporte. Tal fato denota a necessidade de se utilizar políticas organizacionais e tecnologias adequadas para minimizar os seus impactos.

A fragilidade dos documentos digitais e a obsolescência das tecnologias da informação podem acarretar grandes perdas de registros contemporâneos, o que causaria uma lacuna inimaginável na memória das sociedades. Desta forma, não só a memória seria comprometida, mas todos os serviços que dependem da informação registrada em meio digital. No contexto atual não há garantia de acesso futuro, mesmo que se preservem os suportes nos quais os documentos digitais estão registrados. Além da preservação física é preciso dispor dos softwares requeridos para a correta leitura do conteúdo binário.

Enquanto os softwares estão evoluindo para novas versões e formatos, há documentos que não estão acompanhando essa atualização, e por consequência, ficam em formatos e versões obsoletas. Este "esquecimento" poderá ser responsável pela incompatibilidade de diversas funcionalidades dos documentos, como também impossibilitar a leitura do mesmo, perdendo-se o acesso ao seu conteúdo informacional. A obsolescência tecnológica está causando a perca e a inacessibilidade dos documentos digitais, além disso, é inevitável colocar sobre dúvida a fidedignidade destes registros digitais, por causa de sua facilidade de adulteração sem deixar vestígios aparentes.

Destaca-se neste ponto, que a perda, a inacessibilidade, os erros de leitura e as dúvidas com relação a fidedignidade dos documentos digitais são peculiaridades de sua natureza digital, tendo sua origem na obsolescência tecnológica. Desta forma, pode-se considerar que os principais impactos pertinentes aos documentos digitais são a dificuldade de acesso, as dúvidas quanto a integridade e autenticidade de seus conteúdos, e sua consequente perda em virtude da falta de confiança para ser utilizado com fonte de informação. 
A longevidade da informação digital está seriamente ameaçada pela rápida obsolescência tecnológica de hardware, software, formatos de arquivo e suporte (CONARQ, 2004). Os ciclos de obsolescência cada vez menores e a fragilidade dos suportes estão causando a inacessibilidade dos documentos digitais, o que configura uma grande vulnerabilidade (LOPES, V., 2008; ROCHA; SILVA, 2007).

\section{[...] enquanto se fala em "décadas", "séculos" e "milênios" para a preservação de documentos em suportes tradicionais, para os documentos eletrônicos a unidade de medida de tempo é bem diferente. Alguns suportes eletrônicos tem previsão de durabilidade de até duas décadas, mas os programas e equipamentos utilizados para a recuperação e o processamento das informações armazenadas nesses suportes têm vida útil contada em anos e, até, em meses. (SANTOS, V., 2005, p. 58).}

Considerando que há os documentos digitais que devem permanecer acessíveis por longos períodos de tempo, os problemas decorrentes da obsolescência tecnológica tornam-se inevitáveis. De tal forma, o problema se tornará maior ainda devido ao volume de documentos digitais acumulados com o tempo (HEMINGER; ROBERTSON, 2000). Um maior número de documentos implica no aumento da responsabilidade da custódia, bem como, muito provavelmente, em maior diversidade de materiais digitais. Com estes atributos, a preservação se torna mais complexa e consequentemente, exige maiores investimentos.

A tecnologia da informação continuará evoluindo, e desta forma, gerações de hardware, software e suportes se tornarão sucessivamente obsoletas. Neste sentido, mesmo transferindo os documentos digitais de forma idêntica para novos suportes poderá ocorrer a incompatibilidade entre o software criador e o "novo" software utilizado na recuperação dos documentos (HEDSTROM, 2001). A incompatibilidade entre versões e formatos será responsável por erros na leitura, podendo causar alterações nos documentos. Agravantes como estes reforçam a necessidade de se garantir a interoperabilidade entre softwares interpretadores, bem como entre os formatos de arquivo.

A praticidade e a eficiência das ferramentas de tecnologia da informação vêm catalisando novos avanços, muitos de valor ímpar para a sociedade contemporânea. Pode-se dizer que na era das tecnologias, tudo está evoluindo, e tudo esta se tornando obsoleto.

[...] as novas mídias são transitórias, portanto desenvolvem suas funções por um período limitado de tempo, e que é absolutamente necessário implementar a migração sucessiva para novas mídias. As máquinas e programas também caem em desuso, agora em questão de anos e não mais em questão de décadas; o material humano pode também sofrer obsolescência no sentido de que as transformações são muito rápidas e precisam ser acompanhadas, conhecidas e estudadas pelos profissionais envolvidos (MANINI, 2008, p. 179).

A rápida obsolescência das tecnologias causa incertezas quanto ao contexto tecnológico de hardware, software e suporte, e quanto aos conhecimentos sobre estes. Na medida em que não houver conhecimentos suficientes sobre o material a ser preservado, não haverá garantias de recuperação em longo prazo. Neste sentido, identifica-se a necessidade de práticas como a gestão do conhecimento, de modo que venha a apoiar as atividades de preservação digital.

\section{Da conscientização organizacional ao planejamento}

Qualquer atividade relacionada com a preservação digital deverá ser inicialmente planejada e avaliada para que possa ser executada a posteriori. Para que isto aconteça, as partes envolvidas devem se comprometer em garantir os recursos necessários para as atividades em longo prazo.

Vive-se em um cenário onde os produtores não estão preocupados com a preservação dos conteúdos, logo, as políticas de preservação digital raramente são implementadas. Dentre os fatores que dificultam as atividades de preservação, podem-se destacar os custos, o tempo necessário para o planejamento e a estrutura organizacional variada (MÁRDERO ARELLANO, 2004). A preocupação com a preservação digital é o primeiro passo para se elaborar uma política organizacional, sem ela não há razões para se começar um trabalho longo e que exige investimentos. Entretanto além da vontade é preciso ter recursos suficientes e disponíveis em todas as etapas do trabalho, e assim planejá-las detalhadamente.

Na era da "Sociedade da Informação", a preservação digital se configura como um grande desafio em virtude da demanda por tecnologias digitais. Neste sentido, o surgimento do documento digital deixou a comunidade com grandes indagações quanto a sua preservação em longo prazo (INNARELLI 2011). Não há soluções prontas, 
nem experiências que possam servir como exemplo. O documento digital é muito recente, da mesma forma, as práticas existentes não podem ter sua eficácia plenamente comprovada em virtude do fator temporal. Entretanto, é preciso agir, pesquisar e propor soluções, mesmo que estas só possam ser comprovadas a priori. O planejamento da preservação digital trabalha com possibilidades e variações e não com situações estáticas e repetitivas.

A preservação de documentos digitais deve se iniciar até mesmo antes da criação dos documentos, contemplando o planejamento no que se refere a capacidade das ferramentas de tecnologia da informação. Além disso, é preciso que os documentos inseridos em sistemas informatizados estejam em conformidade com as normas organizacionais (SANTOS, V., 2012). Os sistemas devem garantir requisitos como os de integridade e autenticidade dos documentos. Além disso, deve-se fazer uso de tecnologias que garantam a preservação em longo prazo destes registros. Desta forma, torna-se fundamental o uso de emuladores, conversores, dentre outras ferramentas.

\section{Os desafios e as perspectivas da preservação em longo prazo}

A preservação digital está inserida em um contexto de incertezas, apenas com soluções relativas, nenhuma absoluta. Isto quer dizer que há métodos para a preservação de aspectos específicos, mas sua aplicabilidade não pode ser generalizada em virtude da diversidade de recursos digitais.

O desafio da preservação digital consiste em garantir o acesso aos documentos em longo prazo, sendo compatível com um contexto tecnológico diferente de sua criação. Para o seu atingimento há um empecilho, que é a obsolescência tecnológica. Neste sentido, os meios para evitar ou mesmo minimizar os efeitos da obsolescência tecnológica são as estratégias de preservação digital, as quais devem ser executas seguindo um plano de preservação definido nas políticas organizacionais.

As estratégias de preservação digital podem ser classificadas como estruturais e operacionais. As estruturais estão mais relacionadas com a questão das políticas como as de planejamento, alocação de recursos e definição de padrões. Já as estratégias operacionais se direcionam a manutenção dos documentos digitais com relação a sua preservação física, lógica e intelectual (MÁRDERO ARELLANO, 2004; THOMAZ, 2004).

Com relação as estratégias operacionais, há diversos autores que destacam as estratégias de migração, emulação, encapsulamento, refrescamento e preservação da tecnologia (FERREIRA, 2006; MÁRDERO ARELLANO, 2008; ROTHENBERG, 1999; SANTOS, H.; FLORES, 2014b; SANTOS, V., 2005; SARAMAGO, 2002; THIBODEAU, 2002; THOMAZ, 2004). Pode-se dizer que estão são as estratégias implementadas com mais frequência pelas organizações. Além disso, é possível encontrar um corpus teórico considerável sobre seus conceitos, suas vantagens e suas desvantagens.

Através das estratégias de preservação digital é possível minimizar certos efeitos da obsolescência tecnológica. O refrescamento atuará na preservação do nível físico do objeto, desta forma, poderá reduzir os efeitos da obsolescência em nível de suporte, bem como os impactos da degradação do mesmo. O ato de recopiar os conteúdos em suportes mais novos configura uma importante atividade para garantir o acesso aos documentos digitais.

As estratégias de preservação de tecnologia, emulação e encapsulamento atuam na preservação do nível lógico do objeto, ou seja, a manutenção da sequência de bits em sua concepção original. Desta forma, podem-se recuperar os documentos com alto grau de fidedignidade, pois não há manipulações em seu conteúdo binário. A preservação de tecnologia tem como base a manutenção de todo o hardware e software utilizados na concepção dos documentos digitais, garantindo uma interpretação fidedigna. Porém esta estratégia causa grande dependência de hardwares e softwares específicos, o que vem a agravar os impactos da obsolescência tecnológica. A emulação elimina a dependência de um hardware específico, porém, os documentos ficam dependentes do software emulador, o qual também poderá sofrer obsolescência com o passar do tempo. 0 encapsulamento tem por finalidade reunir todo o material necessário para a correta interpretação dos documentos, desta forma, é possível recuperá-los através de estratégias de emulação ou mesmo pelo desenvolvimento de conversores e visualizadores. Sendo assim, o encapsulamento deverá vir acompanhado de uma descrição dos componentes digitais inseridos junto aos documentos, para que desta forma se conheça o seu funcionamento. Outra alternativa transformar o documento encapsulado em um auto-executável, o que se torna mais complexo na medida em que há uma diversidade de formatos de arquivo nos acervos. 
As estratégias de migração estão centradas na preservação do nível conceitual dos documentos, ou seja, objetivam garantir a compatibilidade e a representação do conteúdo. Esta estratégia busca atualizar os formatos e as versões dos documentos a fim de manter-se sempre atualizados, evitando os problemas como a obsolescência. Entretanto, a migração causa alterações nas sequências de bits, podendo levar a erros de representação e perda de dados. Além disso, com o tempo determinados fabricantes deixam de disponibilizar atualizações de seus produtos.

Além da implementação das estratégias de migração, emulação, encapsulamento, refrescamento e preservação da tecnologia, é preciso realizar um monitoramento dos documentos digitais através de sistemas informatizados de gestão e preservação. Destaca-se a importância de ferramentas que verifiquem a integridade dos documentos digitais e seus respectivos componentes, e ferramentas que realizem trilhas de auditoria.

As atividades de preservação digital devem constituir políticas organizacionais que definam as estratégias de preservação de modo que se possam minimizar os efeitos da obsolescência tecnológica, bem como aumentar os níveis de segurança dos documentos digitais. Desta forma, utilizando tecnologias regidas por políticas organizacionais é possível minimizar as fragilidades destes novos registros.

\section{Conclusões}

Este estudo realizou uma breve revisão de literatura abordando a demanda por tecnologias da informação e o consequente advento dos documentos digitais na sociedade. Neste sentido, destacaram-se peculiaridades dos documentos quanto a sua fragilidade e obsolescência tecnológica, apontando seus principais impactos para as sociedades contemporâneas.

Oriundo da evolução das tecnologias da informação, o documento digital apresenta uma série de complexidades e especificidades com relação ao seu tratamento. Diferentemente dos documentos tradicionais, os digitais revolucionaram os modos de transmitir informações e conhecimentos entre pessoas e organizações. Os documentos digitais proporcionam facilidade de comunicação, sendo disseminados através da Internet.

Entretanto, os registros em dígitos binários são mais frágeis que os registros tradicionais, além disso, a sua interpretação ocorre de forma indireta, mediada por computador. Não bastassem estes empecilhos, as tecnologias de hardware, software e suporte estão em constante mudança, o que torna os documentos digitais mais vulneráveis devido a dificuldades de recuperação. Questões como a fragilidade e a vulnerabilidade denotam a necessidade de discussões mais profundas sobre a obsolescência tecnológica e a preservação digital, que são questões muito pertinentes na atualidade.

Uma das questões-chave para o entendimento do problema é que as tecnologias não vão parar de evoluir e consequentemente deixar a geração anterior obsoleta, ou seja, a obsolescência tecnológica é inevitável. Logo, a preservação digital não pode solucionar os problemas de obsolescência, mas pode minimizar os seus impactos frente aos documentos digitais, evitando assim a perda de registros relevantes para a sociedade.

Pode-se dizer que políticas, estratégias e sistemas informatizados são os caminhos para minimizar estes impactos. As políticas definem o que deverá ser preservado, as estratégias executam as atividades e os sistemas informatizados gerenciam as atividades em alto nível, podendo verificar a conformidade com o que foi definido nas políticas de preservação.

Através da sincronia entre estratégias, políticas e sistemas informatizados, será possível identificar e tratar os documentos em formatos e versões obsoletas, através do monitoramento pelos sistemas, bem como definir padrões para a preservação em longo prazo. Uma política de preservação que defina o uso de formatos padronizados para a preservação desde produção dos documentos reduz o risco de obsolescência. E com a padronização de formatos de arquivo, a implementação de estratégias de preservação será mais simples, pois a variedade de formatos será reduzida. Além disso, outras medidas podem ser adotadas como o uso de software livre e de código aberto, o qual possua uma licença de redistribuição, visando assim, não depender das atualizações dos desenvolvedores. Desta forma, caso um software ou formato de arquivo torne-se obsoleto, e consequentemente, deixe de receber atualizações, será possível recriá-lo através do seu código fonte.

Dentre as estratégias de preservação digital, migração, emulação, encapsulamento, refrescamento e preservação de tecnologia, são estratégias operacionais de grande relevância, mas que não podem ser executadas isoladamente em um acervo. É preciso definir um plano de preservação que contemple um conjunto de estratégias para preservar os níveis físico, lógico e conceitual dos documentos digitais. 
Em linhas gerais, os impactos da rápida evolução da tecnologia da informação podem ser observados nos ciclos cada vez mais curtos de obsolescência. O documento digital, inserido neste contexto de constante mudança tecnológica, corre o risco de se perder para sempre, deixando lacunas irrecuperáveis na memória social. Por fim, destaca-se a necessidade de estudos que abordem questões como as estratégias de preservação e os sistemas informatizados. Somente através da sincronia entre políticas, estratégias e sistemas, que será possível minimizar os riscos de perda para níveis considerados seguros.

\section{Referências}

BELLOTTO, Heloísa Liberalli. Arquivos permanentes: tratamento documental. 4. Ed. Rio de Janeiro: Fundação Getúlio Vargas, 2006.

BODÊ, Ernesto Carlos. Preservação de acervos documentais eletrônicos. Revista Brasileira de Arqueometria, Restauração e Conservação. Olinda, v.1, n.2, 2007, p. 32-35. Disponível em: <http://www.restaurabr.org/siterestaurabr/volumesarc/arc02pdf/07preservacaodeacervos.pdf>. Acesso em: 15 dez. 2014.

CONSELHO NACIONAL DE ARQUIVOS - CONARQ (Brasil). Câmara Técnica de documentos eletrônicos. Carta para a Preservação do Patrimônio Arquivístico Digital. Rio de Janeiro: Arquivo Nacional, 2004. Disponível em: $<$ http://www.conarq.arquivonacional.gov.br/Media/publicacoes/cartapreservpatrimarqdigitalconarq2004.pdf>. Acesso em: 10 ago. 2014.

CORRÊA, Amarílis Montagnolli Gomes. Preservação digital: autenticidade e integridade de documentos em bibliotecas digitais de teses e dissertações. Dissertação (Mestrado em Ciência da Informação) 96 p. Universidade de São Paulo, São Paulo, 2010. Disponível em: <http://www.teses.usp.br/teses/disponiveis/27/27151/tde-05112010-105831/pt-br.php>. Acesso em: 03 jul. 2014

FERREIRA, Miguel. Introdução à preservação digital: conceitos, estratégias e atuais consensos, Portugal: Escola de Engenharia da Universidade do Minho, 2006. Disponível em: $<$ https://repositorium.sdum.uminho.pt/bitstream/1822/5820/1/livro.pdf>. Acesso em: 02 ago. 2014.

GIL, Antônio Carlos. Como elaborar projetos de pesquisa. São Paulo: Atlas, 1991.

HEDSTROM, Margaret. Digital Preservation: Problems and Prospects. University of Michigan, USA, 2001. Disponível em: <http://www.dl.slis.tsukuba.ac.jp/DLjournal/No 20/1-hedstrom/1-hedstrom.html >. Acesso em: 10 jan. 2015.

HEMINGER, Alan R; ROBERTSON, Steven B. The Digital Rosetta Stone: a model for maintaining long-term access to static digital documents. Communications of AIS. Vol. 3, Article 2, January 2000. Disponível em: $<$ http://dl.acm.org/citation.cfm?id=374497\&dl=ACM\&coll=DL\&CFTOK>. Acesso em: 24 set. 2014.

INNARELLI, Humberto Celeste. Preservação digital e seus dez mandamentos. In: SANTOS, Vanderlei Batista (Org.). Arquivística: temas contemporâneos, classificação, preservação digital, gestão do conhecimento. Distrito Federal: SENAC, 2007. p. 21-75

INNARELLI, Humberto Celeste. Preservação digital: a influência da gestão dos documentos digitais na preservação da informação e da cultura. Revista Digital de Biblioteconomia e Ciência da Informação, Campinas, v.8, n. 2, p. $72-87$ jan./jun. 2011. Disponível em: <http://www.sbu.unicamp.br/seer/ojs/index.php/rbci/article/view/487/330>. Acesso em: 07 jul. 2014

LOPES, Luís Carlos. A gestão da informação: as organizações, os arquivos e a informação aplicada. Rio de Janeiro: Arquivo Público do Estado do Rio de Janeiro. 1997. 143p.

LOPES, Luís Carlos. A informação e os arquivos: teorias e práticas. Niterói: EDUFF, 1996.

LOPES, Vitor. Preservação Digital. Portugal: Universidade do Minho, Guimarães, 2008. Disponível em: $<$ http://www.vitorlopes.com/Trabalhos/Preservacao Digital-Vitor Lopes.pdf>. Acesso em: 28 ago. 2012.

LUNA, Sergio Vasconcelos de. Planejamento de pesquisa: uma introdução. São Paulo: EDUC, 1997.

MANINI, Miriam Paula. A fotografia como registro e como documento de arquivo. In: Gestão em arquivologia: abordagens múltiplas. Linete Bartalo e Nádina Aparecida Moreno (Orgs.). Londrina: EDUEL, 2008. 188p. p. 119-183.

MÁRDERO ARELLANO, Miguel Ángel. Critérios para a preservação digital da informação científica. 354 p. Tese (Doutorado em Ciência da Informação). Universidade Federal de Brasília, Departamento de Ciência da Informação, 2008. Disponível em: <http://bdtd.bce.unb.br/tedesimplificado/tde busca/arquivo.php?codArquivo=4547>. Acesso em: 15 jun. 2014.

MÁRDERO ARELLANO, Miguel Ángel. Preservação de documentos digitais, Ciência da Informação, Brasília, v. 33, n. 2, p. 15-27, maio/ago. 2004. Disponível em: <http://revista.ibict.br/ciinf/index.php/ciinf/article/view/305/1452>. Acesso em: 25 jul. 2014. 
ROCHA, Claudia Lacombe; SILVA, Margareth da. Padrões para Garantir a Preservação e o Acesso aos Documentos Digitais. Acervo, Rio de Janeiro, v. 20, № 1-2, p. 113-124, jan/dez 2007. Disponível em:

<http://www.revistaacervo.an.gov.br/seer/index.php/info/article/view/142>. Acesso em: 07 set. 2014.

ROTHENBERG, Jeff. Avoiding technological quicksand: finding a viable technical foundation for digital preservation. Commission on Preservation and Access and Council on Library and Information Resources: a report to the Council on Library and Information Resources. EUA: Washington, DC, 1999. Disponível em:

$<$ http://www.clir.org/pubs/reports/rothenberg/pub77.pdf>. Acesso em: 24 set. 2014

SANTOS, Henrique Machado dos; FLORES, Daniel. As estratégias de emulação como fundamento para a preservação de objetos digitais interativos: a garantia de acesso fidedigno em longo prazo. Informação Arquivística, Rio de Janeiro, v. 3, n. 1, p. 95-116, jan./jun., 2014a. Disponível em: <http://www.aaerj.org.br/ojs/index.php/informacaoarquivistica/article/view/79/34> Acesso em: 22 mar. 2015

SANTOS, Henrique Machado dos; FLORES, Daniel. Estratégias de preservação digital em arquivos: garantia de autenticidade e acesso contínuo em longo prazo. In: CONGRESSO NACIONAL DE ARQUIVOLOGIA, 6., 2014, Santa Maria. Anais eletrônicos... Santa Maria: AARS, 2014b. Disponível em: <http://pt.slideshare. net/dfloresbr/arquivologia-sustentabilidade-einovao-vi-congresso-nacional-de-arquivologia-anais-do-vi-cna-2014>. Acesso em: 21 mar. 2015.

SANTOS, Vanderlei Batista dos. Gestão de documentos eletrônicos: uma visão arquivística. $2^{\mathrm{a}}$ Ed. Rev. Aum. Brasília ABARQ, 2005

SANTOS, Vanderlei Batista dos. Preservação de documentos arquivísticos digitais. Ciência da Informação, Brasília, DF, v. 41 n. 1, p.114-126, jan./abr., 2012. Disponível em: <http://revista.ibict.br/index.php/ciinf/article/view/2110/1797>. Acesso em: 20 Dez. 2014.

SARAMAGO, Maria de Lurdes. Metadados para preservação digital e aplicação do modelo OAIS. In: CONGRESSO NACIONAL DE BIBLIOTECARIOS, ARQUIVISTAS E DOCUMENTALISTAS, ํo 08. 2004, Estoril. Anais eletrônicos... Disponível em: <http://www.bad.pt/publicacoes/index.php/congressosbad/article/view/640/637>. Acesso em: 04 jul. 2014.

SARAMAGO, Maria de Lurdes. Preservação digital a longo prazo: boas práticas e estratégias. Cadernos BAD, Lisboa, 2002, n 2, p. 54-68. Disponível em: <http://www.bad.pt/publicacoes/index.php/cadernos/article/view/866>. Acesso em: 10 fev. 2015.

SAYÃO, Luis Fernando. Uma outra face dos metadados: informações para a gestão da preservação digital. Enc. Bibli: R. Eletr. Bibliotecon. Ci. Inf., Florianópolis, v. 15, n. 30, p.1-31, 2010. Disponível em: $<$ https://periodicos. ufsc.br/index.php/eb/article/view/1518-2924.2010v15n30p1/19527>. Acesso em: 10 fev. 2015.

SAYÃO, Luis Fernando; SALES, Luana Farias. Curadoria digital: um novo patamar para preservação de dados digitais de pesquisa. Inf. \& Soc.: Est., João Pessoa, v.22, n.3, p. 179-191, set./dez. 2012. Disponível em: $<$ http://www.ies.ufpb.br/ojs2/index.php/ies/article/view/12224/8586>. Acesso em: 22 mar. 2015.

SILVA, Edna Lúcia da; MENEZES, Estera Muszkat. Metodologia da pesquisa e elaboração de dissertação. 4. Ed. rev., Florianópolis: UFSC, 2005. Disponível em: $<$ https://projetos.inf.ufsc.br/arquivos/Metodologia de pesquisa e elaboracao de teses e dissertacoes 4ed.pdf >. Acesso em: 13 jun. 2014.

THIBODEAU, Kenneth. Overview of Technological Approaches to Digital Preservation and Challenges in Coming Years, presented at The State of Digital Preservation: An International Perspective, Washington D.C., 2002. Disponível em: <http://www.clir.org/pubs/reports/pub107/thibodeau.html>. Acesso em: 19 Ago. 2014.

THOMAZ, Kátia de Pádua. A preservação de documentos eletrônicos de caráter arquivístico: novos desafios, velhos problemas. 389f. Tese (Doutorado em Ciência da Informação). Escola de Ciência da Informação. Universidade Federal de Minas Gerais, 2004. Disponível em: <http://www.bibliotecadigital.ufmg.br/dspace/bitstream/handle/1843/VALA68ZRKF/doutorado katia de padua thomaz.pdf>. Acesso em: 28 jul. 2014.

THOMAZ, Kátia de Pádua. Gestão e preservação de documentos eletrônicos de arquivo: revisão de literatura - parte 2. Arquivística.net, Rio de Janeiro, v.2, n.1, p.114-131, jan./.jun. 2006. Disponível em: <www.brapci.ufpr.br/download.php?dd0=6733>. $\quad$ Acesso $\quad$ em: $07 \quad$ set. 2014. 


\section{Dados dos autores}

Henrique Machado dos Santos

Possui graduação em Arquivologia pela Universidade Federal de Santa Maria (2014). É membro do grupo de pesquisa CNPq: GED/A. Tem experiência na área de Ciência da Informação, com ênfase em Arquivologia, atuando principalmente nos seguintes temas: preservação digital, obsolescência tecnológica, tecnologia da informação, documento arquivístico digital e software livre.

henrique.gralha@gmail.com

Daniel Flores

Doutor em Metodologías y Líneas de Investigación en Biblioteconomía y Documentación pela Universidad de Salamanca (USal), Espanha. Professor Adjunto do Departamento de Documentação da Universidade Federal de Santa Maria (UFSM).

dfloresbr@gmail.com

$\begin{array}{ll}\text { Recebido-Received } & : 2015-04-30 \\ \text { Aceitado-Accepted } & : 2015-06-26\end{array}$

1 http://www. periodicos.capes.gov.br/ 